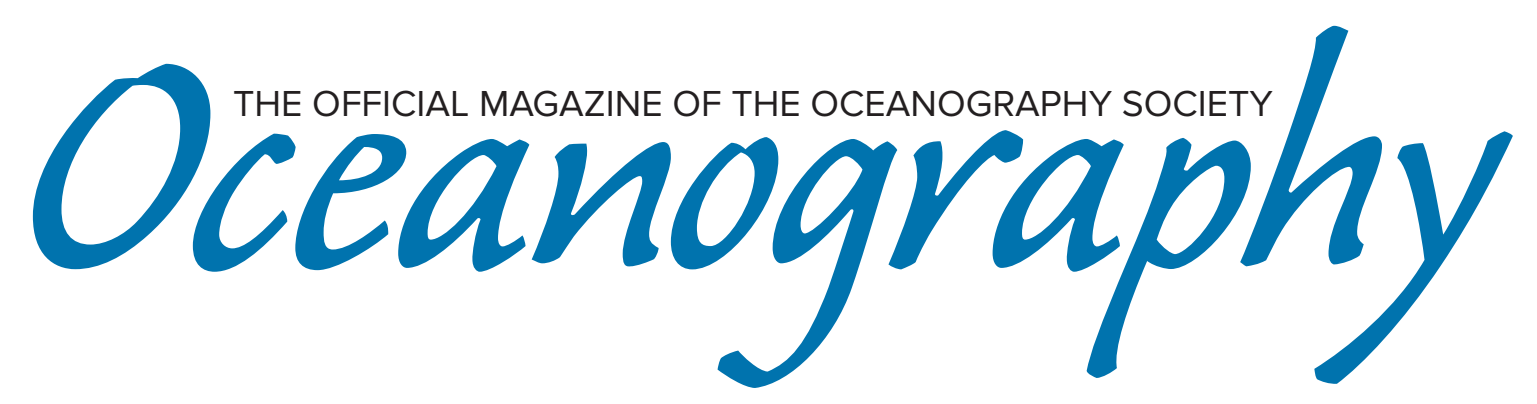

CITATION

Kappel, E.S. 2017. Using Oceanography in the classroom-Insight from a survey of TOS members. Oceanography 30(4):4-5, https://doi.org/10.5670/oceanog.2017.400.

$\mathrm{DOI}$

https://doi.org/10.5670/oceanog.2017.400

COPYRIGHT

This article has been published in Oceanography, Volume 30, Number 4, a quarterly journal of The Oceanography Society. Copyright 2017 by The Oceanography Society. All rights reserved.

\title{
USAGE
}

Permission is granted to copy this article for use in teaching and research.

Republication, systematic reproduction, or collective redistribution of any portion of this article by photocopy machine, reposting, or other means is permitted only with the approval of The Oceanography Society. Send all correspondence to: info@tos.org or The Oceanography Society, PO Box 1931, Rockville, MD 20849-1931, USA. 


\section{Using Oceanography in the Classroom- Insight from a Survey of TOS Members}

In connection with The Oceanography Society's thirtieth anniversary in mid-November, TOS sent members an email requesting that they complete a short survey to enable us to understand how they have used Oceanography magazine to support the Society mission to advance education in the ocean sciences. The survey contained just three questions:

1. Have you ever assigned Oceanography articles in the classroom as a basis for discussion?

2. Have you used graphics from Oceanography articles in your lectures?

3. Tell us more about how you use Oceanography articles or special issues in the classroom or for other educational purposes such as informing policymakers or management. Please name specific special issues or articles that you have found most useful for classroom discussions.

We limited the survey to three questions to maximize the number of respondents, and restricted the survey to TOS members to keep things simple and ensure a rapid response. We were rewarded. As of November 29, and within two weeks of its posting, 200 TOS members had taken the survey.

Figures 1 and 2 show the responses to the simple multiple choice questions. Figure 1 shows that nearly half of the survey respondents have used one or more Oceanography articles in the classroom during a semester, with most in the one-to-three article range. Figure 2 shows that about $60 \%$ of respondents have used Oceanography graphics in lectures, with a considerable

QUESTION 1. Have you ever assigned Oceanography articles in the classroom as a basis for discussion?

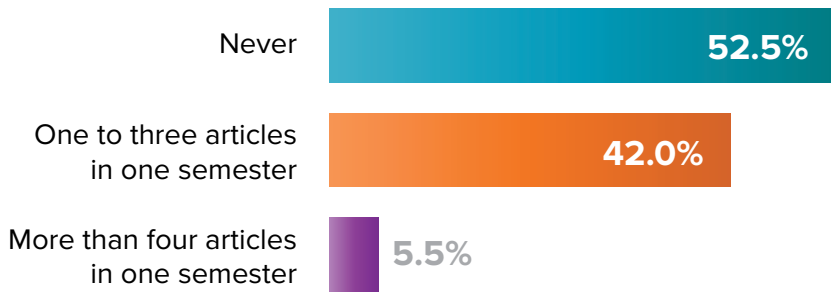

FIGURE 1. Responses from TOS members to Question $1(n=200)$. percentage-13.5\%-using more than four graphics. These numbers are very satisfying and demonstrate that Oceanography is widely used for educational purposes. One note of caution about these numbers, though: we know from the Question 3 responses that several student members completed the survey, so the number of "never" responses may be artificially high.

After the two simple warm-up questions, the "essay question"Question 3-provided exactly the sort of specific information we were seeking about how TOS members use Oceanography for education and outreach purposes. Table 1 is a small selection of several of the 143 responses we received to Question 3, edited to fit. In addition to the classroom uses of Oceanography articles described in Table 1, one response said that they "display Oceanography in our undergraduate office where we meet prospective students and their parents. It is a wonderful conversation starter." Another said: "I use it as an advising tool to orient students interested in careers in marine science." Another member wrote: "Occasionally use graphics to support new program briefs to management." Yet another member wrote: "Provide issues from time to time to US Congressperson from my Congressional District, US Senators from my state and Staff (mainly for the staff)." All of the responses will be very useful in helping TOS articulate the broader impacts of Oceanography to current and future sponsors. The answers also provided some ideas about how we may improve the usefulness of articles and graphics-for example, by providing individual graphics that are easily downloaded for classroom use.

\section{QUESTION 2. Have you used graphics from} Oceanography articles in your lectures?

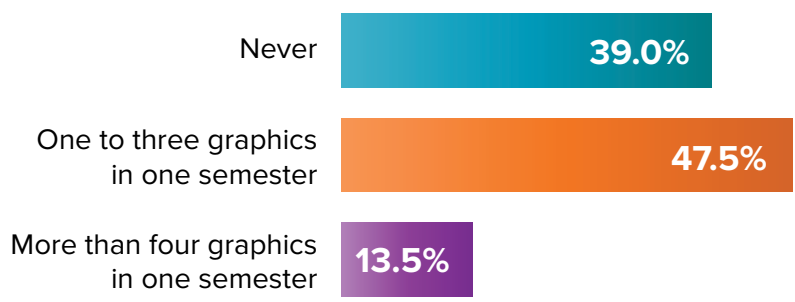

FIGURE 2. Responses from TOS members to Question $2(n=200)$. 
Thanks to all of the TOS members who participated in the survey. We were truly overwhelmed by the response. If you did not receive the survey email, or forgot to respond, we would still like to hear from you, especially regarding Question 3. You can email me your response at ekappel@geo-prose.com, or if you are attending the Ocean Sciences Meeting in February, please come by the TOS booth and share your stories about how you use Oceanography in the classroom and also how we might make the magazine more useful for educational purposes. For those of you who responded to the survey online and will be attending the Ocean Sciences Meeting, come to the TOS booth and chat with us anyway-and also collect your extra beverage coupon.

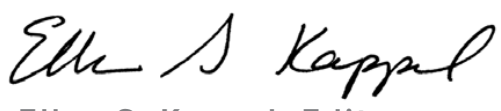

Ellen S. Kappel, Editor

TABLE 1. Selection of Responses to Question 3 from November 2017 Online Survey of TOS Members $(n=143)$

QUESTION 3. Tell us more about how you use Oceanography articles or special issues in the classroom or for other educational purposes such as informing policymakers or management. Please name specific special issues or articles that you have found most useful for classroom discussions.

I have used graphics from Oceanography in many lectures over the years. It's one of the best sources for clear and easy-to-understand illustrations and images of scientific processes. Pictures of people at sea are great for showing young people why a career in oceanography can be exciting!

I assign and discuss Oceanography articles that are relevant to courses and lectures. The fact that the articles are by practicing scientists but (usually) written at a level that engages undergraduates makes them useful to introduce students to the topic and primary literature.

I use them as current review articles in classes "Biological Oceanography" and "Anthropogenic Changes in the Ocean." Oceanography has very didactic graphs and concentrated, but simple to understand texts. Maybe you could describe it as a wide-ranging, up to date Oceanography textbook.

Many of the articles are concise summaries that are especially appropriate for lower division introductory classes.

We regularly use TOS articles for our first year graduate students taking our topic-driven seminar class. The TOS articles are excellent for overview material that the students must then flesh out with additional readings from the literature and then present meeting style presentation and then lead follow-up discussion.
I have consistently recommended the articles to the community college instructors in professional development activities that I undertake.

I particularly like the "big picture" articles for classroom settings. For example, there was a special issue several years ago on larval dispersal. Much of the provided information included basic concepts in the field that aren't readily available in a BioOce textbook.

Special issues are great for framing an issue, especially for instructors with high teaching loads who might not otherwise have much time to research a topic.

Oceanography special issues are great compendiums of articles on a single topic-bathymetry, ice-ocean exchange, etc.-and these are really helpful for getting students up to speed on a topic.

I find that they provide great summaries on a lot of topics for my students as well as for myself when I prepare lectures. The graphics are usually high quality and illustrate broader concepts, which are great for classroom lectures.

The articles are available to all students and have become staples in my graduate classes. I have and continue to use too many to list here. 